\title{
Repercussões psicossociais da dependência funcional no cotidiano de idosos longevos
}

\author{
Pollyanna Viana Lima, ${ }^{1}$ Tatiane Dias Casimiro Valença, ${ }^{2}$ Luciana Araújo dos Reis ${ }^{3}$
}

\section{Resumo}

O objetivo deste estudo é conhecer e discutir as repercussões psicossociais da dependência funcional no cotidiano de idosos longevos de uma Unidade de Saúde da Família. Trata-se de um estudo exploratório-descritivo, com abordagem qualitativa, realizado em uma Unidade de Saúde da Família, sendo os participantes representados por sete idosos longevos, classificados com dependência funcional e sem déficit cognitivo. $\mathrm{O}$ instrumento de coleta foi constituído por uma entrevista semidirigida, mediada por questões norteadoras. Para a análise dos dados, foi aplicada análise de conteúdo temático-categorial. Da análise de conteúdo, emergiram duas categorias, a saber: "Repercussões sociais da dependência" e "Repercussões psicológicas da dependência". Ficou evidente, entre as repercussões psicológicas, a presença de sentimentos de medo, tristeza e depressão. Em relação às repercussões so- ciais, as principais encontradas foram a redução nas relações sociais e o isolamento social, com consequente solidão.

Palavras-chave: Envelhecimento. Idosos. Incapacidade Funcional. Longevidade.

\section{Introdução}

Conforme Camarano (2011), a demarcação do início da velhice é complexa, pois envolve questões sociais, econômicas, regionais, culturais, étnicas e de gênero. Logo, não há como precisar uma definição exata de marcação para a fase da vida em que a pessoa pode ser considerada idosa, pois, segundo a mesma autora, tal transição pode estar relacionada a várias questões: "biológicas,

1 Enfermeira. Mestre e doutoranda do Programa de Pós-Graduação em Memória: Linguagem e Sociedade, da Universidade Estadual do Sudoeste da Bahia (Uesb), campus de Vitória da Conquista, BA - Brasil. Integrante do Núcleo de Estudos e Pesquisas sobre Envelhecimento e Obesidade. Pesquisadora do núcleo de extensão, pesquisa e estudos sobre Doenças Crônicas, da Universidade Estadual do Sudoeste da Bahia.E-mail:polly_vl@ yahoo.com.br

2 Fisioterapeuta (Ucsal). Mestre em Enfermagem e Saúde (Uesb). Doutoranda do Programa de Pós-Graduação em Memória: Linguagem e Sociedade (PPGM/Uesb). Docente Assistente do Curso de Fisioterapia da Universidade Estadual do Sudoeste da Bahia (Uesb). E-mail: tatidcv@ig.com.br

3 Fisioterapeuta (Uesb). Especialista em Saúde Pública (Facinter). Especialista em Ativação de Processos de Mudança na Formação Saúde (Fiocruz). Mestre e Doutora em Ciências da Saúde (UFRN). Pós-Doutoramento em Saúde Coletiva (UFBA-ISC). Docente Adjunto B do Curso de Fisioterapia (Uesb). Orientadora do Programa de Pós-graduação em Memória: Linguagem e Sociedade (Uesb). Coordenadora do Núcleo de Estudos e Pesquisa sobre Envelhecimento e 0besidade. Pesquisadora líder do núcleo de extensão, pesquisa e estudos sobre Doenças Crônicas. E-mail: ucianauesb@ yahoo.com.br

$\rightarrow$ http://dx.doi.org/10.5335/rbceh.v13i2.6370

Recebido em: 07.09.2016. Aceito em: 31.07.2017. 
aparência física, surgimento de doenças crônicas, perda de capacidades físicas, mentais e de papéis sociais, nascimento de netos, entre outros" (CAMARANO, 2008, p. 130).

A partir de uma demarcação cronológica, a Política Nacional do Idoso define o idoso como um indivíduo com 60 anos ou mais (BRASIL, 2010). Concorda-se com Camarano (2011) que esse conceito baseado na idade cronológica é um tanto limitante, pois coloca o idoso numa homogeneidade, sem considerar as trajetórias de vida de cada indivíduo, suas condições econômicas, de gênero e de raça, ou seja, não considera outras dimensões às quais o sujeito está exposto. Todavia, para este estudo, foi necessário delimitar uma idade cronológica para a qual se considerou a população de 80 anos ou mais, aqui definida como idosos longevos (LENARDT; CARNEIRO, 2013).

Estudos demográficos têm demonstrado o crescente aumento da população idosa no mundo e também no Brasil. Os dados de projeção do Instituto Brasileiro de Geografia e Estatística (IBGE) indicam que a esperança de vida ao nascer em 2014 era de 71,6 anos para homens e 78,8 anos para mulheres e que, em 2060 , deve atingir 78,0 e 84,4 anos, respectivamente (IBGE, 2015).

O processo de envelhecimento ocorre de maneira singular e complexa e varia de acordo com cada pessoa, dependendo de fatores biológicos, psicológicos e sociais (CHAIMOWICZ, 2013). Nesse sentido, um idoso pode chegar à longevidade, apresentando capacidade funcional preservada e independência funcional de outros, porém, há idosos que passam dos 80 anos de idade e podem enfrentar a dependência funcional, aqui caracterizada como a incapacidade de manter a independência física e mental (GORDILHO, 2000). Um idoso dependente funcionalmente apresenta dificuldade ou necessidade de ajuda para executar tarefas no seu dia a dia, tanto as atividades básicas como as instrumentais da vida diária (MINOSSO et al., 2010).

Nos últimos anos, tem ocorrido um expressivo aumento do comprometimento funcional em idosos, principalmente para os que se encontram na faixa acima de 80 anos de idade (NOGUEIRA et al., 2010). Por isso, a capacidade funcional é um excelente marcador de como tem sido vivida a longevidade, bem como do estado de saúde dos idosos, pois a existência de múltiplas patologias, especialmente as crônicas não transmissíveis, pode influenciar no desenvolvimento e no comprometimento dessa capacidade (BARBOSA et al., 2014).

A Dependência Funcional de idosos longevos tem repercussões físicas e psicológicas. Essas repercussões, quando negativas, são comprometedoras da capacidade funcional, da independência e da autonomia e, também, têm implicações sociais que invadem todos os aspectos da vida (LOURENÇO et al., 2012). Além dessas consequências, a dependência traz, ainda, implicações para a família, para a comunidade, para o sistema de saúde, mas, sobretudo, para a individualidade dos idosos, uma vez que contribui para a redução de bem-estar e da qualidade de vida (BRITO et 
al., 2013). Acrescenta-se a isso o fato de a dependência funcional ter um impacto dramático sobre a expectativa de vida, o que aumenta a necessidade de sua avaliação contínua (KEELER et al., 2010).

Diante disso, é importante frisar que as equipes de saúde devem realizar avaliações da capacidade funcional de forma frequente no atendimento ao idoso, especialmente o longevo, haja vista a necessidade de intervir aos primeiros sinais de dependência funcional.

Portanto, diante do breve exposto, salienta-se que a dependência funcional é um problema de saúde pública (GRATÃO et al., 2013), que precisa de uma atenção particular, o que torna fundamental a realização de estudos que tratem da temática com o intuito principal de subsidiar políticas públicas que venham a atender as demandas advindas dessa dificuldade.

Foi observado que, na literatura científica, as pesquisas em relação à dependência funcional estão mais voltadas para as repercussões físicas, e são poucos os trabalhos que abordam as repercussões psicossociais desse quadro. Diante disso, emergiu o seguinte questionamento: quais as repercussões psicossociais da dependência funcional no cotidiano de idosos longevos?

Na busca por respostas a essa pergunta, este estudo teve como objetivo conhecer e discutir as repercussões psicossociais da dependência funcional na vida de idosos longevos de uma Unidade de Saúde da Família (USF ) no município de Vitória da Conquista/BA.

\section{Materiais e métodos}

Trata-se de um estudo exploratório, descritivo, com abordagem qualitativa, realizado com sete idosos de idade igual ou superior a 80 anos (idosos longevos), de ambos os sexos, que apresentam dependência funcional e fazem parte dos bairros de abrangência de uma Unidade de Saúde da Família do município de Vitória da Conquista/BA.

Os critérios utilizados para inclusão dos participantes neste estudo foram: idosos com dependência funcional avaliados a partir do Índice de Barthel (incluindo os idosos que apresentaram pontuação abaixo de 100 pontos) e da Escala de Lawton (incluindo os idosos com pontuação abaixo de 27 pontos); idosos que apresentavam condições mentais aceitáveis para responder ao instrumento da pesquisa, avaliados a partir da aplicação do Mini Exame do Estado Mental (Meem), versão reduzida (BERTOLUCC et al., 1994).

Para a avaliação da dependência funcional, aplicou-se o Índice de Barthel e a Escala de Lawton. O primeiro é utilizado para avaliar capacidade funcional e é composto por dez atividades: alimentação, banho, higiene pessoal, vestuário, eliminação intestinal, eliminação vesical, transferência para higiene íntima, transferência cadeira e cama, deambulação e escadas, com uma quantificação de pontos que de varia de 0-100. Nesse índice, o indivíduo que atingir 100 pontos é independente. Pontuações até 75 pontos correspondem à dependência leve, até 50 pontos, dependência moderada e abaixo 
de 25 pontos indicam dependência grave (MAHONEY; BARTHEL, 1965).

A Escala de Lawton é utilizada para avaliar a capacidade funcional para atividades mais complexas, imprescindíveis para uma vida social mais autônoma, como: telefonar, efetuar compras, preparar as refeições, usar meios de transporte, etc. Cada questão possui três opções de resposta: independência (3 pontos); dependência parcial ( 2 pontos); e dependência total (1 ponto). A pontuação vai de 9 a 27 pontos, sendo que, quanto maior o escore, maior será o grau de independência (LAWTON; BRODY, 1969).

Para a avaliação do estado mental, aplicou-se o Mini Exame do Estado Mental de Pfeiffer, que é composto por 10 perguntas que avaliam quatro parâmetros: memória a curto e longo prazo, orientação, informações do cotidiano e capacidade de cálculo. Em sua versão reduzida, a pontuação é feita da seguinte forma: 0-2 erros - funcionamento mental normal; 3-4 erros - defeito cognitivo ligeiro; 5-7 erros - defeito cognitivo moderado; 8 ou mais erros - defeito cognitivo grave. A pontuação máxima é de 10 pontos (BERTOLUCC et al., 1994).

Durante o período da pesquisa, foram identificados trinta e quatro idosos longevos cadastrados na USF. Eles foram visitados pelas pesquisadoras em companhia de Agentes Comunitários de saúde (ACS), para uma conversa rápida e a aplicação dos testes de capacidade funcional (Índice Barthel e Escala de Lawton) e de cognição (Meem). Após a aplicação dos testes, dezesseis idosos foram classificados como funcionalmen- te dependentes, porém, cinco deles não ofereceram condições cognitivas preservadas para responder à entrevista, pois apresentaram pontuação $\leq 24$ pontos no teste de cognição. Assim, onze idosos foram caracterizados como dependentes funcionais e com o estado cognitivo preservado. Porém, desses, apenas sete aceitaram participar do estudo.

Para a coleta dos dados, foram utilizados dois instrumentos. O primeiro instrumento foi um questionário sociodemográfico e econômico, constituído de perguntas referentes à caracterização dos participantes, como: sexo, idade, estado civil, escolaridade, religião, profissão anterior, renda e moradia, e relativo à saúde, como patologias e sequelas. $\mathrm{O}$ segundo instrumento foi uma entrevista semiestruturada, elaborada pelas pesquisadoras, com a seguinte questão: 0 que mudou na vida do senhor(a) após o momento que passou a ser dependente de outras pessoas? As entrevistas ocorreram na residência do idoso, no período de janeiro a março de 2015, em horário agendado previamente com o entrevistado. As falas foram gravadas em áudio com conhecimento e consentimento do idoso.

Para a análise dos dados, foi utilizada a análise de conteúdo temática (BARDIN, 2011). Com base nessa técnica, a organização da análise ocorreu em torno de três etapas: pré-análise, exploração do material e tratamento dos resultados, inferência e interpretação.

Este estudo, extraído em parte da dissertação de mestrado intitulada Envelhecer com dependência funcional: memó- 
ria de idosos longevos, foi aprovado pelo comitê de Ética em Pesquisa da Faculdade Independente do Nordeste, parecer $\mathrm{n}^{\circ}$ 759.441, CAAE: 33683514.1.0000.5578. Todos os participantes tiveram pleno conhecimento do estudo e de seus objetivos, assinando o termo de Consentimento Livre e Esclarecido, de acordo com a Resolução no. 466/12 para pesquisa com seres humanos. Os nomes dos participantes foram alterados, para preservar o anonimato e garantir a confidencialidade, sendo identificados com as letras IL (Idoso Longevo) seguidas da numeração de 1 a 7 .

\section{Resultados e discussão}

Os resultados do questionário sociodemográfico apresentaram os seguintes dados: a idade média dos idosos foi de 87,2 anos, com maioria do sexo masculino $(\mathrm{n}=5)$. Quanto à escolaridade, houve variação: analfabeto $(\mathrm{n}=2)$, alfabetizado $(\mathrm{n}=3)$, ensino fundamental $(\mathrm{n}=1)$ e ensino médio $(\mathrm{n}=1)$. A renda familiar predominante foi a de um salário mínimo, obtido a partir da aposentadoria. As ocupações foram: trabalhador rural $(n=2)$, professora $(n=1)$, ferreiro $(n=1)$, motorista $(n=1)$, mecânico $(n=1)$, do lar $(n=1)$. Em relação à religião, os entrevistados se denominaram católicos $(n=4)$, evangélicos $(n=2)$ e espírita $(n=1)$. As patologias apontadas entre os entrevistados mostraram o predomínio da hipertensão arterial sistêmica $(n=6)$, seguida de osteoporose $(n=2)$, artrose $(n=3)$, cardiopatia $(n=2)$, trombose pulmonar $(n=1)$ e gastrite $(n=1)$.
A entrevista semiestruturada permitiu conhecer o olhar dos idosos participantes deste estudo acerca das repercussões psicossociais. As informações foram expressas em duas categorias que se seguem: "Repercussões psicossociais da dependência" e "Repercussões sociais da dependência".

\section{Repercussões psicossociais da dependência}

Existem diversas maneiras de perceber e vivenciar o envelhecer. Essa fase do ciclo vital pode ser percebida como um período positivo, o qual é enfatizado por felicidade, união familiar, experiência de vida, tempo para aproveitar a vida. Contudo, para outros, pode ser percebida como algo negativo devido à presença de doenças, solidão, medo, perda de vigor físico e emocional (MENESES et al., 2013).

A tristeza e o medo foram mencionados em três relatos dos idosos entrevistados:

O que tem mais em mim é tristeza (IL1).

Eu sempre fiz tudo sozinha. Criei esses três filhos tudo sozinha, sem ajuda, hoje eu que preciso de ajuda pra tudo. Fico triste com isso (IL2).

Eu não saio. Ajunta o medo de eu cair na rua e me arrebentar todo e a tristeza é tanta que eu não acho mais coragem, aquela vontade, aquela coisa de... aquele prazer de sair. $\mathrm{E} \mathrm{a}$ minha vida eu levo assim. E o mais de mim é tristeza (IL3).

Tais relatos corroboram com estudo realizado no município de Cascavel/PR, 
com idosos dependentes, no qual ficou constado que a dependência funcional provocou sentimentos de ansiedade, tristeza, irritação, medo e a necessidade de adaptação a um novo estilo de vida (TAVARES, et al., 2012). As dificuldades em realizar atividades da vida diária são aspectos que ameaçam o bem-estar individual e podem gerar angústia, sentimentos de solidão, problemas de saúde mental e quadro sintomático depressivo.

Esses sentimentos negativos podem agravar-se e determinar sintomas de um quadro depressivo, podendo ser potencializado pela dependência funcional, haja vista que o idoso longevo dependente está em uma situação de perdas continuadas, e elas despertam, muitas vezes, sentimentos de desânimo e tristeza (TEIXEIRA, 2010). Nesse sentido, os idosos dependentes que apresentam doenças crônicas e limitações funcionais podem ser mais vulneráveis a sentimentos de tristeza e melancolia que podem levar ao isolamento social e à instalação de um quadro de depressão (MOTA, 2013).

Segundo a Organização Pan-Americana da Saúde (OPAS, 2016), a depressão pode ser caracterizada por tristeza persistente, falta de interesse e deficiência de energia. Também é ressaltado que o envelhecimento e suas consequências favorecem o risco para a depressão, especialmente a partir dos 85 anos de idade, devido a problemas, como incapacidade de locomoção, diminuição da visão, prejuízo cognitivo leve, entre outros fatores (WANNMACHER, 2016).

Nas falas a seguir, é possível perceber que os idosos sentem-se desanima- dos, desestimulados, deprimidos, cansados em face às dificuldades em lidar com a impossibilidade de realizar ações que desempenhavam normalmente.

Não tem nada pra fazer mesmo. Na cozinha eu não faço nada, não aguento, aí fico aqui, nessa salinha sentada (IL1).

Você vai perdendo o ânimo das coisas, o estímulo. Quando a gente fica pensando o que fazer e não tem mais condição de fazer. Fico deprimida, deprimida, porque a gente percebe que a pessoa também já está cansada (IL2).

Nessa idade eu não tenho mais a saúde que eu tinha antes. Eu não tenho apetite pra comer, não tenho mais forças (IL3).

Pode-se observar, em um estudo realizado com 63 participantes, os quais foram divididos em dois grupos: um com idosos dependentes e outro com idosos independentes, que o grupo com idosos dependentes apresentou maiores níveis de depressão do que o grupo de idosos ativos, concluindo que a percentagem de idosos com sintomatologia depressiva é significativamente superior $(72,4 \%)$ no conjunto dos idosos dependentes do que no conjunto de idosos ativos $(41,2 \%)$ (MOTA, 2013). Desse modo, as perdas com que o idoso dependente se depara, tais como o aumento da solidão, o afastamento do mundo exterior e o isolamento social, contribuem certamente para o aumento de sintomas depressivos (MOTA, 2013).

Portanto, tais sentimentos ampliam o risco de os idosos dependentes necessitarem de uma rede de suporte assistencial em suas vidas. Daí a importância da inserção dos idosos em grupos de apoio e em ações socioeducacionais. Além 
disso, é preciso que a equipe de atenção básica seja atuante por meio de visitas domiciliares, as quais devem objetivar o fortalecimento da relação e da interação da Unidade Básica de Saúde com o idoso e a família, no intuito de prevenir ou minimizar o aparecimento da solidão, da tristeza e da depressão (MENESES et al., 2013). As relações familiares e sociais são imprescindíveis para a manutenção da qualidade de vida de idosos (PINTO; OLIVEIRA, 2015).

Acrescenta-se a isso a importância de investir em esforços na manutenção da independência e da autonomia de idosos, especialmente os longevos, pois a independência e a autonomia são determinantes para uma boa qualidade de vida e possibilita envelhecer com prazer (PINTO; NERI, 2013).

\section{Repercussões sociais da dependência}

Segundo uma pesquisa realizada pelo psicólogo John Cacioppo, diretor do Centro de Neurociência Cognitiva e Social da Universidade de Chicago (EUA), a solidão amplia em $14 \%$ o risco de morte prematura para idosos. Cacioppo (apud OLIVEIRA, 2014) ainda acrescenta que idosos que se encontram afastados das relações sociais se deparam com mais problemas de pressão arterial, insônia, memória e complicações cardiovasculares.

A solidão é um fenômeno complexo de significado amplo e subjetivo, depende da maneira como cada pessoa, perante determinada situação, avalia o seu estado de solidão e de que forma a suporta. A maioria das pessoas idosas, especialmente as dependentes funcionalmente, reduz a sua participação na comunidade, o que pode originar sentimentos de solidão e desvalorização, com efeitos ao nível da integração social e familiar e ao nível da saúde física e psíquica (TEIXEIRA, 2010).

Ficou nítida essa realidade no corpus do estudo, pois alguns idosos mencionaram a inexistência de participação na comunidade e o afastamento das relações sociais devido à limitação funcional.

Agora só fico em casa. Não saio mais, a não ser pra ir pro médico e vou de táxi, porque ônibus não pego mais. Não consigo (IL1).

Minha vida é esse paradeiro. Nunca mais eu vi nada. Nunca mais eu sair. Só saio mesmo pra ir pra médico e pronto (IL2).

É daqui pra dentro do quarto e de dentro do quarto pra sala ou no portão. Daí pra cá. Tenho uns amigos aí que fala fulano você não vai em minha casa e eu falo, num vou não é porque eu não tenho condição de ir (IL3).

$\mathrm{Eu}$ frequentava muito os encontros que tinha aí no posto de saúde, no prédio da igreja, era da terceira idade, mas hoje eu não frequento mais, porque está lá no centro da cidade. Para ir preciso de alguém pra me levar, não posso mais pegar ônibus sozinho (IL4).

Sinto falta dos meus amigos do trabalho, hoje não posso encontrar mais com eles, porque eu tô doente, não aguento viajar mais e nem eles também, tão doente também (IL5).

A realidade mencionada por esses idosos condiz com o estado atual de limitação funcional, pois eles não têm a possibilidade de sair, visitar amigos, ir aos encontros de grupos de terceira idade, ir à igreja, entre outras atividades cotidianas. Assim, deixam de exercer 
atividades do dia a dia com outras pessoas, e esse fato traz sofrimento, tristeza e redução de convívio social (LOPES, R.; LOPES, M.; CAMARA, 2009).

As relações sociais entre os mais velhos estimulam a mente e o pensamento, com múltiplos efeitos benéficos sobre a saúde e o bem-estar e, ainda, contribuindo para a melhoria da qualidade de vida. Além disso, é importante mencionar que o suporte social auxilia no melhoramento nos níveis de saúde (RODRIGUES; SILVA, 2013), em oposição à ruptura dos laços sociais que podem gerar doenças (ALVARENGA et al., 2011).

As redes de apoio social são fundamentais para o convívio social do idoso dependente, pois colaboram para que eles se sintam queridos, valorizados e tenham o sentimento de que pertencem a um grupo(RODRIGUES; SILVA, 2013). Portanto, faz-se necessário possibilitar-lhes algumas formas de incremento nas redes de apoio social, pois a necessidade do outro é mais fortemente desejada na velhice, no sentido que "A objetividade orgânica da velhice, aliada à condição pessoal de ser velho, remete os indivíduos às vivências primeiras de necessidade do outro para manter-se vivo" (PY; TREIN, 2002).

A velhice associada ao comprometimento da capacidade funcional faz com que o idoso tenha muitas perdas, sejam profissionais, financeiras, familiares, de saúde, entre tantas outras (TEIXEIRA, 2010). Assim, o apoio social tem função importante no enfretamento dessas perdas e limitações da velhice, pois pode contribuir para manutenção ou ainda promoção da saúde física e mental dos idosos (RODRIGUES; SILVA, 2013). O apoio social se caracteriza pelos recursos disponibilizados por grupos e/ou pessoas com quem os idosos mantêm contatos sistemáticos que derivam em efeitos emocionais e/ou comportamentos positivos (AMARAL; NASCIMENTO; FALCÃO, 2013).

Um estudo com idosos atendidos por equipes de Saúde da Família concluiu que a rede de suporte social dos idosos é pequena na maioria das dimensões avaliadas, e o sistema provedor mais presente é o familiar (ALVARENGA et al., 2011). Esse achado corrobora com o presente estudo, pois a maior parte do apoio social dos idosos vem da família.

$\mathrm{O}$ apoio maior é da família. Eles sempre estão de acordo comigo em tudo que eu quero. É só coisa para o bem, então eles estão sempre comigo (IL4).

A minha família, apesar de pequena, está sempre perto, mesmo que demora uns dias, um mês, mas está sempre por perto, liga, vem aqui me ver (IL6).

Quando se fala em família aqui, a referência é feita aos mais próximos, como, por exemplo: filhos(as), esposos(as), netos(as), genro(s) e nora(s). Vale ressaltar que apenas dois idosos têm como cuidadoras suas filhas, os demais são as netas que oferecem o suporte mais de perto. Nesse sentido, a família continua sendo o centro de solidariedade intergeracional para os idosos, especialmente os dependentes, ao desempenhar uma função fundamental no restabelecimento e na manutenção de saúde e bem-estar dos seus membros (SEBASTIÃO; ALBUQUERQUE, 2011). 
Além do apoio da família, é importante frisar a rede social de apoio aos idosos. O termo rede social de apoio refere-se a um grupo de pessoas que tem contato frequente, ou seja, indivíduos que interagem, realizam trocas e fazem parte de um processo dinâmico, muitas vezes complexo, mas que pode satisfazer parte das necessidades sociais de um indivíduo. Essas redes sociais de apoio produzem conectividades, homogeneidade e estabilidades (RODRIGUES; SILVA, 2013), o que favorece ao idoso uma melhor qualidade de vida (NERI, 2001).

No estudo realizado por Freitas (2011), os resultados obtidos apontaram o papel importante que a rede social pode desempenhar como estratégia para lidar com a experiência da solidão. $\mathrm{O}$ estudo também evidenciou que, quanto maior a rede social, menor a escala de solidão e, quanto menor é a rede, maior a probabilidade de o indivíduo sentir-se solitário.

Outros estudos têm revelado que o envolvimento familiar e social pode influenciar diretamente na saúde dos idosos dependentes, em seu bem-estar psicológico e na satisfação com a vida (BRITO; PAVARINI, 2012; FRANCINE; PINTO, 2015).

Outra repercussão social demonstrada pelos idosos é a solidão. Percebeu-se, especialmente em dois idosos deste estudo, esse sentimento. O IL3 demonstrou durante toda entrevista ser vítima de solidão, pois, além dele não poder sair para visitar amigos, eles também não o visitam, a família, que mora longe, o vê esporadicamente e os que estão próximos, como diz o próprio idoso, es- queceram que ele existe, como podemos observar em sua fala. Em contrapartida, a IL7 diz que, mesmo tendo companhia, tem o sentimento de solidão:

\begin{abstract}
Me sinto muito mal, fico triste, choro por causa da solidão (IL3).

Ajunta a solidão. Tenho meu povo aqui, mas assim, não tenho ninguém pra conversar com uns aos outros. Eu sou só. Eu fico aqui aguardado aqui dentro de casa (IL3).

Meus filhos não pode me visitar, porque eles têm os trabalhos deles, não pode abandonar... eles demoram um monte de ano sem vi aqui, só liga e, quando eu aguento atender, eu atendo...assim é nossa comunicação (IL3).

A solidão é uma coisa ruim demais. Tenho solidão mesmo tendo companhia de algumas pessoas (IL7).
\end{abstract}

Pode ser observado na fala da IL7 que ela tem companhia, mas apresenta o sentimento de solidão. A solidão se manifesta mais nitidamente na companhia de outras pessoas, assim, não é necessário estar sozinho para ter solidão, isso porque esse é um sentimento subjetivo (ARENDT, 2006). Muitas vezes, uma pessoa se vê cercada por outros com os quais não pode estabelecer contato, ou seja, coexiste uma hostilidade.

Pode-se dizer que ocorre um ciclo vicioso, no qual a dependência funcional pode gerar uma alteração psicossocial na vida do idoso dependente, provocando sentimentos de tristeza e solidão, chegando até a depressão. Esses sentimentos vão comprometer ainda mais a realização das atividades diárias desses idosos e gerar mais isolamento social. Esse ciclo se repete e perdura, comprometendo a qualidade de vida 
desses indivíduos, provocando um sentimento de vazio interior cada vez maior (RODRIGUES; SILVA, 2013).

\section{Conclusão}

A partir desse estudo foi possível conhecer e compreender as repercussões psicossociais no cotidiano de idosos com dependência funcional de uma Unidade de saúde do Município de Vitória da Conquista/BA. Ficou evidente, entre as repercussões psicológicas, a presença de sentimentos de medo, tristeza e depressão. Com relação às repercussões sociais, as principais encontradas foram a redução nas relações, seja no ambiente familiar, de trabalho, entre outros, e o isolamento social. A associação dessas repercussões se mostrou como a principal causa para a solidão desses indivíduos e consequentemente para o aumento da sua incapacidade funcional, dependência e declínio da qualidade de vida.

As limitações desta pesquisa se dão tanto pela falta de outras pesquisas na área, para que haja uma possível comparação, quanto pela não generalização dos seus resultados para toda a população a cima de 60 anos de idade, pois este estudo representa um grupo específico de pessoas idosas, cadastradas em uma Unidade de Saúde no município de Vitória da Conquista/BA.

Estudos a respeito desse tema se mostram fundamentais para que os profissionais da área da saúde que proporcionam o cuidado aos idosos longevos com dependência funcional percebam que os problemas afetam além do aspec- to físico e funcional. A repercussão da presença de uma dependência funcional se dá nos âmbitos sociais, emocionais, individuais e familiares da pessoa idosa, e esses aspectos precisam ser observados para que possam ser elaboradas estratégias de ação que atendam às demandas do idoso longevo dependente em sua totalidade.

\section{Psychosocial repercussions of functional dependence in the daily life of long-lived elderly}

\section{Abstract}

The aim of this study is to know and discuss the psychosocial repercussions of functional dependence in the daily life of long-lived elderly citizens of a Family Health Unit located. It is a this is an exploratory-descriptive study, with qualitative approach, conducted in a Family Health Unit, and the participants were represented by seven long-lived elderly citizens, classified with functional dependence and without cognitive deficit. The instrument was composed by a semi-directed interview mediated by guiding questions. In order to analyze data, we applied the analysis of thematic-categorical content. The content analysis gave rise to two categories, namely: "Social repercussions dependence" and "emotional repercussions of Dependence". Amid the psychological repercussions, it became clear the presence of feelings of fear, sadness and depression. Concerning the social repercussions, the reduction in social relationships and social isolation, with consequent loneliness.

Keywords: Aging. Elderly. Functional Incapacity. Longevity. 


\section{Referências}

ALVARENGA, M. R. M. et al. Rede de suporte social do idoso atendido por equipes de Saúde da Família. Revista Ciência \& Saúde Coletiva, Rio de Janeiro (RJ), v. 16, n. 5, p. 2603-2611, maio 2011. Disponível em: <http://www.scielo.br/pdf/csc/v16n5/ a30v16n5.pdf $>$. Acesso em: 20 jun. 2016.

AMARAL, F. L. J. S.; NASCIMENTO, A, F.; FALCÃO, A. C. C. M. Perfil do apoio social de idosos no município de Natal RN. Epidemiologia e Serviço de Saúde, Brasília (DF), v. 22 , n. 2 , p. 335-346, abr./jun. 2013. Disponível em: <http://scielo.iec.pa.gov.br/pdf/ ess/v22n2/v22n2a15.pdf $>$. Acesso em: 22 maio 2016.

ARENDT, H. Origens do Totalitarismo. Tradução de Roberto Raposo. São Paulo: Companhia das Letras, 2006.

BARBOSA, B. R. et al. Avaliação da capacidade funcional dos idosos e fatores associados à incapacidade. Revista Ciência \& Saúde Coletiva, Rio de Janeiro (RJ), v. 19, n. 8, p. 3317-3325，2014. Disponível em: <http:// www.scielosp.org/pdf/csc/v19n8/1413-8123csc-19-08-03317.pdf>. Acesso em: 15 maio 2016.

BARDIN L. Análise de conteúdo. Lisboa: Edições 70, 2011.

BERTOLUCC, P. H. F. et al. Mini-exame do estado mental em uma população geral: impacto da escolaridade. Arquivo Neuropsiquiatric, São Paulo, v. 52, n. 1, p. 01-07, 1994. Disponível em: <http://www.scielo.br/pdf/ anp/v52n1/01.pdf>. Acesso em: 17 jun. 2016.

BRASIL. Lei $n^{\circ}$ 8.842. Política Nacional do Idoso, de janeiro de 1994. 1. ed. Brasília, 2010. Disponível em: <http://www.planalto. gov.br/ccivil_03/leis/l8842.htm>. Acesso em: 11 maio 2016.

BRITO, T. A; FERNANDES, M. H.; COQUEIRO, R. S.; JESUS, C. Falls and functional capacity in the oldest old dwelling in the community. Texto e Contexto Enfer- magem, Florianópolis, v. 22, n. 1, p. 43-51, jan./mar. 2013. Disponível em: <http://www. scielo.br/pdf/tce/v22n1/06.pdf >. Acesso em: 04 ago. 2016.

BRITO, T. R. P; PAVARINI S. C. I. A relação entre o apoio social e capacidade funcional em idosos com alterações cognitivas. Revista Latino Americana de Enfermagem, Ribeirão Preto, SP, v. 20, n. 4, p. 677-684, jul./ago. 2012. Disponível em: <http://www.scielo.br/scielo.php?pid=S0104$-11692012000400007 \& \mathrm{script}=\mathrm{sci}$ arttext\&tlng=pt>. Acesso em: 22 maio 2016.

CAMARANO, A. A. A demografia e o envelhecimento populacional. In: BORGES, A. P. A.; COIMBRA, A. M. C. Envelhecimento e Saúde da Pessoa Idosa. Fundação Oswaldo Cruz. Escola Nacional de Saúde Pública Sergio Arouca. Educação a Distância. Rio de Janeiro: EAD/ENSP, ago. 2008. Disponível em: <http://www5.ensp.fiocruz.br/biblioteca/ dados/txt_912998204.pdf>. Acesso em: 14 abr. 2016.

Envelhecimento da população brasileira: continuação de uma tendência. Revista Coletiva, Rio de Janeiro, n. 5, 2011. Disponível em: <http://www.coletiva.org/site/index. php?option=com_k2\&view=item\&layout $=\mathrm{i}$ tem $\& \mathrm{id}=58 \&$ Itemid $=76 \& \mathrm{idrev}=8>$. Acesso em: 12 abr. 2016.

CHAIMOWICZ, F. Saúde do idoso, Belo Horizonte, 2013. Disponível em: <http://sbgg. org.br/wp-content/uploads/2014/10/saude-do-idoso-2edicao-revisada.pdf>. Acesso em: $1^{\circ}$ jun. 2016.

FRANCINE, N. F. R; PINTO, D. C. O. Capacidade funcional e envolvimento social em idosos: há relação? RBCEH, Passo Fundo, RS, v. 12 , n. 1, p. 56-68, jan./abr. 2015. Disponível em: <http://www.upf.br/seer/index. $\mathrm{php} / \mathrm{rbceh} /$ article/viewFile/4687/pdf $>$. Acesso em: 20 jul. 2016.

FREITAS, P. C. B. Solidão em idosos: percepção em função da rede social. 2011. Dissertação (Mestrado em Ciências Sociais)-Universidade Católica Portuguesa, 
Braga, jun. 2011. Disponível em: <http://repositorio.ucp.pt/bitstream/10400.14/8364/1/ SOLID\%C3\%830\%20EM\%20IDOSOS.pdf>. Acesso em: $1^{\circ}$ jul. 2016.

GORDILHO, A. et al. Desafios a serem enfrentados no terceiro milênio pelo setor saúde na atenção ao idoso. Rio de Janeiro: UnATI, 2000.

GRATÃO, A. C. M. et al. Dependência funcional de idosos e a sobrecarga do cuidador. $R e$ vista da Escola de enfermagem da USP, São Paulo, v. 47, n. 1, p. 137-44, 2013. Disponível em: <http://www.scielo.br/pdf/reeusp/v47n1/ a17v47n1.pdf>. Acesso em: 04 ago. 2016.

IBGE - INSTITUTO BRASILEIRO DE GEOGRAFIA E ESTATÍSTICA. Diretoria de Pesquisas Coordenação de População e Indicadores Sociais. Rio de janeiro, 2015. Disponível em: <ftp://ftp.ibge.gov.br/Tabuas_Completas_de_Mortalidade/Tabuas_Completas_de_Mortalidade_2014/notastecnicas. pdf>. Acesso em: 11 maio 2016.

KEELER, E. et al. The impact of functional status on life expectancy in older persons. J Gerontol A Biol Sci Med Sci., v. 65, n. 7, p. 727-733, jun. 2010. Disponível em: <http:// www.ncbi.nlm.nih.gov/pubmed/20363833>. Acesso em: 22 jul. 2016.

LAWTON, M. P; BRODY, E. M. Assesment of older people: self-maintaining and instrumental activities of daily living. Gerontologist, v. 9, p, 179-185, 1969. Disponível em: <http://www.eurohex.eu/bibliography/ pdf/Lawton_Gerontol_19691502121986/ Lawton_Gerontol_1969.pdf>. Acesso em: 05 ago. 2016.

LENARDT, M. H.; CARNEIRO, N. H. K. Associação entre as características sociodemográficas e a capacidade funcional de idosos longevos da comunidade. Cogitare Enfermagem, Curitiba, v. 18, n. 1, p. 13-20, jan./mar. 2013. Disponível em: <http://revistas.ufpr.br/ cogitare/article/view/31299/20008>. Acesso em: 04 ago. 2016.
LOPES, R. F.; LOPES, M. T. F.; CAMARA, V. D. Entendendo a solidão do idoso. RBCEH, Passo Fundo, v. 6, n. 3, p. 373-381, set./dez. 2009. Disponível em: <http://seer.upf.br/ index.php/rbceh/article/viewFile/362/818>. Acesso em: 08 ago. 2016.

LOURENÇO, T. M. et al. Capacidade funcional no idoso longevo: uma revisão integrativa. Revista Gaúcha de Enfermagem, Porto Alegre, RS, v. 33, n. 2, p. 176-185, 2012. Disponível em: <http://www.scielo.br/pdf/rgenf/ v33-n2/25.pdf>. Acesso em: 22 jul. 2016.

MAHONEY, F. I.; BARTHEL, D. W. Functional evaluation: the Barthel Index. $M a$ ryland StateMed J., v. 14, p. 56-61, 1965. Disponível em: <http:/www.strokecenter.org/ wp-content/uploads/2011/08/barthel_reprint. pdf $>$. Acesso em: 11 maio 2016.

MENESES, $D$. $L$. $P$. et al. A dupla face da velhice: o olhar de idosos sobre o processo de envelhecimento. Revista Enfermagem em Foco, Brasília, v. 4, n. 1, p. 15-18, jan. 2013. Disponível em: <file:///D:/Downloads/4951281-1-SM\%20(7).pdf>. Acesso em: 14 maio 2016.

MINOSSO, J. S. M. et al. Validação, no Brasil, do Índice de Barthel em idosos atendidos em ambulatórios. Acta paulista de Enfermagem, São Paulo, v. 23, n. 2, p. 218-223, mar./abr. 2010. Disponível em: <http://www. scielo.br/pdf/ape/v23n2/11.pdf>. Acesso em: 14 maio 2016.

MOTA, T. B. Depressão e religiosidade: estudo exploratório na população idosa dependente. 2013. Dissertação (Mestrado em Psicologia)-Universidade de Lisboa, Lisboa, 2013. Disponível em: <http://repositorio. ul.pt/bitstream/10451/10514/1/ulfpie046413_ tm.pdf $>$. Acesso em: 05 jul. 2016.

NERI, A. L. Envelhecimento e qualidade de vida na mulher. In: CONGRESSO PAULISTA DE GERIATRIA E GERONTOLOGIA, 2., 2001, Campinas. Anais... Campinas: Universidade Estadual de Campinas, 2001. p. 01-18. 
NOGUEIRA, S. L. et al. Determinant factors of functional status among the oldest old. Revista Brasileira de Fisioterapia, São Carlos, v. 14, n. 4, p. 322-329, jul./ago. 2010. Disponível em: <http://www.scielo.br/pdf/ rbfis/v14n4/en_aop019_10.pdf>. Acesso em: 08 ago. 2016.

OLIVEIRA, I. Pesquisa: solidão aumenta em $14 \%$ o risco de morte prematura em idosos. 2014. Disponível em: <http://www. correiobraziliense.com.br/app/noticia/cienciaesaude/2014/02/24/interna_ciencia_saude,414284/pesquisa-solidao-aumenta-em-14-o-risco-de-morte-prematura-em-idosos. shtml>. Acesso em: 27 jul. 2016.

PINTO, F. N. F. R.; OLIVEIRA, D. C. Capacidade funcional e envolvimento social em idosos: há relação? Revista Brasileira de Ciências do Envelhecimento Humano, Passo Fundo, RS, v. 12, n. 1, p. 56-68, jan./abr. 2015. Disponível em: <http://seer.upf.br/index.php/ rbceh/article/view/4687/pdf>. Acesso em: 26 jul.2016.

PINTO, J. M.; NERI, A. L. Doenças crônicas, capacidade funcional, envolvimento social e satisfação em idosos comunitários: Estudo Fibra. Ciência \& Saúde Coletiva, Rio de Janeiro, RJ, v. 18, n. 12, p. 3449-3460, 2013. Disponível em: <http://www.scielo.br/scielo.php?pid=S1413$-81232013001200002 \&$ script $=$ sci $_{\text {_ }}$ abstract\&tlng=pt>. Acesso em: 05 ago. 2016.

PY, L.; TREIN, F. Finitude e Infinitude: dimensões do tempo na experiência do envelhecimento. In: FREITAS, E. V. et al. Tratado de geriatria e gerontologia. Rio de Janeiro: Guanabara Koogan, 2002.

RODRIGUES, A. G.; SILVA, A. A. A rede social e os tipos de apoio recebidos por idosos institucionalizados. Revista Brasileira de Geriatria e Gerontologia, Rio de Janeiro, v. 16, n. 1, p. 159-170, 2013. Disponível em: <http:// www.scielo.br/pdf/rbgg/v16n1/a16v16n1. pdf $>$. Acesso em: 20 jun. 2016.
SEBASTIÃO, C.; ALBUQUERQUE, C. Envelhecimento e dependência. Estudo sobre os impactes da dependência de um membro idoso na família e no cuidador principal. $R e$ vista Kairós Gerontologia, São Paulo, v. 14, n. 4, p. 25-49, 2011. Disponível em: <file:///C:/ Users/User/Downloads/10048-24938-1-SM. pdf $>$. Acesso em: 13 maio 2016.

TAVARES, K. O. et al. Envelhecer, adoecer e tornar-se dependente: a visão do idoso. Revista Kairós Gerontologia, São Paulo, v. 15, n. 3, p. 105-118, 2012. Disponível em: <file:///D:/Downloads/8979-33219-1-PB\%20 (15).pdf>. Acesso em: 02 ago. 2016.

TEIXEIRA, L. M. F. Solidão, depressão e qualidade de vida em idosos: um estudo avaliativo exploratório e implementação-piloto de um programa de intervenção. 2010. Dissertação (Mestrado em Psicologia)-Universidade de Lisboa, Lisboa, 2010. Disponível em: <http:// repositorio.ul.pt/bitstream/10451/2608/1/ ulfp037460_tm_tese.pdf $>$. Acesso em: 15 jul. 2016.

WANNMACHER, L. Abordagem da depressão maior em idosos: medidas não medicamentosas e medicamentosas. OPAS / OMS - Representação Brasil, v. 1, n. 1. 2016. Disponível em: <file:///C:/Users/User/Downloads/ Abordagem\%20idosos_F001.pdf $>$. Acesso em: 19 jun. 2016. 